\title{
Chemical Enhancement of Footwear Impressions in Blood on Fabric - Part 3: Amino Acid Staining
}

\author{
Kevin J. Farrugia ${ }^{\text {a,b }}$, Helen Bandey ${ }^{c}$, Kathleen Savage ${ }^{\text {a }}$, Niamh NicDaéid ${ }^{\text {a,* }}$ \\ ${ }^{\text {a }}$ Centre for Forensic Science, WestCHEM, Department of Pure and Applied Chemistry, \\ University of Strathclyde, Glasgow, G1 1XW, UK \\ ${ }^{\mathrm{b}}$ School of Contemporary Sciences, Division of Environment and Forensic Sciences, \\ University of Abertay, Bell Street, Dundee, DD1 1HG, UK \\ ${ }^{c}$ Centre for Applied Science and Technology [formerly HOSDB], Home Office Science, \\ Woodcock Hill, Sandridge, St. Albans, AL4 9HQ, UK
}

* CORRESPONDING AUTHOR

Niamh NicDaéid

Centre for Forensic Science

WestCHEM, Department of Pure and Applied Chemistry

University of Strathclyde

Glasgow, G1 1XW

UK

n.nicdaeid@strath.ac.uk 


\title{
Chemical Enhancement of Footwear Impressions in Blood on Fabric - Part 3: Amino Acid Staining
}

\begin{abstract}
Enhancement of footwear impressions, using ninhydrin or ninhydrin analogues is not considered common practice and such techniques are generally used to target amino acids present in fingermarks where the reaction gives rise to colour and possibly fluorescence. Ninhydrin and two of its analogues were used for the enhancement of footwear impressions in blood on various types, colour and porosities of fabric. Test footwear impressions on fabric were prepared using a specifically built rig to minimise the variability between each impression. Ninhydrin enhancement of footwear impressions in blood on light coloured fabric yielded good enhancement results, however the contrast was weak or non-existent on dark coloured fabrics. Other ninhydrin analogues which have the advantage of fluorescence failed to enhance the impressions in blood on all fabrics. The sequential treatment of impressions in blood on fabric with other blood enhancing reagents (e.g. protein stains and heme reagents) was also investigated.
\end{abstract}

Keywords: footwear impressions, enhancement, blood, fabric, amino acid, ninhydrin, DFO, 1,2-indanedione 


\section{INTRODUCTION}

Ninhydrin is a non-specific amino acid reagent useful for the development of latent fingerprints [1-3]. As amino acids are also present in blood, chemicals that enhance latent fingerprints may also enhance impressions in blood. Bodziak [4] has indicated that ninhydrin is occasionally used to enhance footwear impressions in blood. Furthermore, ninhydrin has been reported as successful in enhancing footwear impressions in blood on paper that had been exposed to rain for over three weeks [5]. The reaction of ninhydrin results in an intermediate colour change, varying from orange to purple (Ruhemann's purple complex) depending on the fingerprint's origin and development conditions [6]. Recent research [7, 8] showed that liquid hydrofluorocarbons such as HFC4310, HFE7100 and HFE71DE are efficient and safe substitute solvents to CFC113 for formulations of ninhydrin and its analogues.

1,8-Diazafluorenone-9-one (DFO) is a ninhydrin analogue developed by Grigg et al. [9]. The reaction of DFO with amino acids gives a magenta colour which is less intense than the one obtained with ninhydrin. The main advantage of DFO is that it exhibits enhancement with both colour and fluorescence [10]. Ninhydrin analogues developed in the 1980s exhibited similar results to ninhydrin itself [11, 12]. 1,2-indanedione (1,2-IND), 5-methylthioninhydrin (5-MTN) and 5-methoxyninhydrin, developed by Heffner and Joullie [13], are reagents utilised for processing latent impression evidence in a similar mechanism to ninhydrin. It has been reported that treated latent impressions produced a bright purple colour that was stronger than ninhydrin [13] and fluoresced stronger than those developed with DFO [14, 15]. Such compounds are known as dual fingerprint reagents as they produce enhanced latent impressions that are both coloured and fluorescent [16].

There are numerous techniques for the enhancement of impressions in blood with new techniques being discussed routinely. However, Kent [17] stresses the importance that "we are not seduced into giving up well-tried and documented methods by superficial attraction of a 'new technique' until we have reliable data". As ninhydrin and some of its analogues are well used and established techniques, this study evaluates these chemical reagents for the enhancement of impressions in blood on fabric with comparison to other reagents previously reported [18-20]. 


\section{MATERIALS AND METHODS}

\subsection{Preparation of test footwear impressions}

Footwear impressions in blood (bovine) on fabric were prepared using a specifically built footwear rig to minimise variables such as pressure and the amount of blood deposited on the substrate [21]. $50 \mathrm{~mL}$ of blood was poured over two Kimberley ${ }^{\circledR}$ blue double ply tissues before the sole was brought in contact with the footwear sole. A stepping motion was then repeated twice on clean tissues to remove excess blood before using the footwear rig to provide a stamping action on the fabric required.

The objective of this work was the comparison of the ability of various amino acid staining techniques to enhance footwear impressions in blood, rather than directly mimic operational conditions normally encountered. The use of the footwear rig to prepare test footwear impressions provided repeatability of the quality of the footwear impression produced which allowed for a direct comparison of the various stains to be robust.

Six repeat impressions for each fabric-enhancement technique were prepared and each impression was aged for 7 days before enhancement. Photography at various stages of the enhancement process of the impression was performed using a Canon EOS 300D [sensor size $\left.22.7 \times 15.1 \mathrm{~mm}\left(3.42 \mathrm{~cm}^{2}\right)\right]$. Appropriate controls of the chemical reagents and calibration of camera and computer monitor were also carried out to ensure the robustness of the study.

\subsection{Chemical Formulations}

The chemical reagents and fabrics utilised in the study are listed in table 1. Ninhydrin, DFO, 1,2-IND, acid black 1 (AB1) and acid yellow 7 (AY7) were prepared as recommended by the Centre for Applied Science and Technology [6, 22]. Fluorescence examination was performed using a Mason Vactron Qauser 40 where the wavelength ranges represent the $1 \%$ cut-on and cut-off points. 
Table 1 - List of Chemicals and Fabrics

\begin{tabular}{|c|c|c|c|c|}
\hline Chemical Name & $\begin{array}{c}\text { Alternative Chemical } \\
\text { Name }\end{array}$ & $\begin{array}{l}\text { Chemical } \\
\text { Supplier }\end{array}$ & Fabric & $\begin{array}{c}\text { Fabric } \\
\text { Supplier }\end{array}$ \\
\hline Ninhydrin & $\begin{array}{l}\text { 2,2-Dihydroxy-1,3- } \\
\text { indanedione }\end{array}$ & $\begin{array}{l}\text { Sigma } \\
\text { Aldrich }\end{array}$ & $\begin{array}{l}\text { White Cotton } \\
\text { (WC) }\end{array}$ & $\begin{array}{l}\text { WBL Whaleys } \\
\text { Bradford Ltd. }\end{array}$ \\
\hline DFO & $\begin{array}{c}\text { 1,8-Diazafluorenone-9- } \\
\text { one }\end{array}$ & BVDA & $\begin{array}{l}\text { Black Cotton } \\
\text { (BC) }\end{array}$ & $\begin{array}{l}\text { WBL Whaleys } \\
\text { Bradford Ltd. }\end{array}$ \\
\hline $1,2-\mathrm{IND}$ & 1,2-indanedione & BVDA & $\begin{array}{c}\text { Patterned } \\
\text { Cotton (PC) }\end{array}$ & $\begin{array}{l}\text { WBL Whaleys } \\
\text { Bradford Ltd. }\end{array}$ \\
\hline $\begin{array}{l}\text { Acid Black } 1 \\
\text { (AB1) }\end{array}$ & Amido Black 10B & BVDA & $\begin{array}{c}\text { White } \\
\text { Polyester } \\
\text { (WPE) }\end{array}$ & $\begin{array}{l}\text { WBL Whaleys } \\
\text { Bradford Ltd. }\end{array}$ \\
\hline Acid Yellow 7 & $\begin{array}{c}\text { Brilliant } \\
\text { Sulfoflavine }\end{array}$ & BVDA & $\begin{array}{c}\text { Black } \\
\text { Polyester } \\
(\mathrm{BPE})\end{array}$ & $\begin{array}{l}\text { WBL Whaleys } \\
\text { Bradford Ltd. }\end{array}$ \\
\hline \multirow[t]{4}{*}{ Luminol } & $\begin{array}{l}\text { 5-Amino-2,3-dihydro- } \\
\text { 1,4-phthalazinedione }\end{array}$ & $\begin{array}{l}\text { Bluestar } \\
\text { Forensic }\end{array}$ & $\begin{array}{l}\text { White Nylon/ } \\
\text { Lycra (WNL) }\end{array}$ & $\begin{array}{l}\text { WBL Whaleys } \\
\text { Bradford Ltd. }\end{array}$ \\
\hline & & & $\begin{array}{l}\text { Black Nylon/ } \\
\text { Lycra(BNL) }\end{array}$ & $\begin{array}{l}\text { WBL Whaleys } \\
\text { Bradford Ltd. }\end{array}$ \\
\hline & & & Denim & $\begin{array}{c}\text { Mandors, } \\
\text { Glasgow, UK }\end{array}$ \\
\hline & & & $\begin{array}{l}\text { Bovine } \\
\text { Leather }\end{array}$ & $\begin{array}{l}\text { The Clyde } \\
\text { Leather Co., } \\
\text { Glasgow, UK }\end{array}$ \\
\hline
\end{tabular}

\subsubsection{Amino acid Stains}

Ninhydrin Concentrated Solution: 25g of ninhydrin (Sigma) was dissolved in 225mL of absolute ethanol (Sigma). 10mL of ethyl acetate (Sigma) followed by $25 \mathrm{~mL}$ of acetic acid (Sigma) was added to the slurry and stirred until a clear yellow solution was produced. The solution will keep for at least 12 months at normal room temperature. 
Ninhydrin Working Solution: 52mL of ninhydrin concentrated solution was measured out followed by the addition of 1L of HFE 7100 (3M Novec) whilst stirring with a magnetic stirrer. The solution will keep for at least 12 months at normal room temperature.

Treatment of articles with Ninhydrin: The fabric was immersed in the working solution for a maximum of five seconds. The excess solution was allowed to drain back in the tray. The fabric was allowed to dry completely before being heated in a humidity oven at $80^{\circ} \mathrm{C}$ for four minutes and at a nominal $65 \%$ relative humidity. Enhancement can occur immediately or within the next few hours/days.

DFO Working Solution: $0.25 \mathrm{~g}$ of DFO was dissolved in $30 \mathrm{~mL}$ of methanol (Sigma) using a magnetic stirrer to produce a slurry. $20 \mathrm{~mL}$ of acetic acid (Sigma) was added and stirred until a clear, yellow solution was produced followed by the addition of 275mL of HFE71DE (3M Novec) and 725mL of HFE7100 (3M Novec) with continued stirring. The solution will keep for at least one month at normal room temperature.

Treatment of articles with DFO: The fabric was immersed in the working solution for a maximum of five seconds. The excess solution was allowed to drain back in the tray. The fabric was allowed to dry completely before being heated in an oven at $100^{\circ} \mathrm{C}$ for 20 minutes without humidifying. Fluorescence examination was carried out using a green excitation filter wavelength of 473-548nm with a viewing Schott filter of 549nm.

1,2-Indanedione Working Solution: 0.25g of 1,2-indanedione (BVDA) was weighed and dissolved using a magnetic stirrer in $90 \mathrm{~mL}$ of ethyl acetate (Sigma), $10 \mathrm{~mL}$ of acetic acid (Sigma) and $0.5 \mathrm{~mL}$ of $\mathrm{ZnCl}_{2}$ stock solution. Finally $1 \mathrm{~L}$ of HFE-7100 (3M Novec) was added to the mixture and stirred.

$\mathrm{ZnCl}_{2}$ Stock Solution: $0.2 \mathrm{~g}$ of anhydrous zinc chloride (BDH) was dissolved in $5 \mathrm{~mL}$ absolute ethanol (Sigma).

Treatment of articles with 1,2-Indanedione: The fabric was immersed in the working solution for a maximum of five seconds. The excess solution was allowed to drain back in the tray. The fabric was allowed to dry completely before being heated in an oven at $100^{\circ} \mathrm{C}$ for 10 
minutes without humidifying. Fluorescence examination was carried out using a green excitation filter wavelength of 473-548nm with a viewing Schott filter of 549nm.

\subsubsection{Protein Stains}

\section{Acid Black 1 and Acid Yellow 7}

Fixing solution: $23 \mathrm{~g}$ of 5-sulfosalicyclic acid dihydrate (Acros) was dissolved and stirred in $1 \mathrm{~L}$ of distilled water. This was used to fix the impressions in blood by immersion for a minimum period of 5 minutes.

Staining solution: $1 \mathrm{~g}$ of acid black 1 or $1 \mathrm{~g}$ of acid yellow 7 (BVDA) was stirred for at least 30 minutes in $50 \mathrm{~mL}$ acetic acid (Sigma), $250 \mathrm{~mL}$ ethanol (Sigma) and $700 \mathrm{~mL}$ distilled water. This was used to stain the impressions by immersion for a minimum period of 3 minutes.

De-staining solution: $50 \mathrm{~mL}$ acetic acid, $250 \mathrm{~mL}$ ethanol and $700 \mathrm{~mL}$ ethanol. This was used to wash the excess dye from the background. All items were let to air dry overnight before photography.

\subsubsection{Luminol}

\section{Luminol}

The luminol formulation in this study was Bluestar ${ }^{\circledR}$ Forensic Magnum purchased from Bluestar ${ }^{\circledR}$ Forensic. It was prepared by dissolving the three tablets in the liquid supplied $(125 \mathrm{~mL})$ and then applied using an Ecospray® unit supplied by Bluestar® Forensic.

Luminol photography: The best photographic quality of the resultant chemiluminescent reactions was obtained using the following conditions: ISO400, f 5.6, exposure of 15 seconds and white balance set on tungsten, 


\subsection{Sequential Chemical Enhancement}

Sequential chemical enhancement was investigated using black cotton and white polyester as exemplars of dark and light, natural and synthetic fabric. Examples of a peroxidase reagent [luminol (LUM)] a protein stain [acid black 1 (AB1)], an amino acid stain [ninhydrin (NIN)] and an alginate (ALG) were used to enhance the impressions on white polyester. For black cotton, AB1 and ninhydrin were replaced with acid yellow 7 (AY7) and DFO respectively as they may provide fluorescence and hence visualisation against the dark background. Six different sequential enhancements were considered as shown in table 2.

Table 2 - Sequential enhancement for impressions in blood on black cotton

\begin{tabular}{|c|c|}
\hline Sequence & Technique Sequence \\
\hline 1 & AY7, LUM, DFO \\
\hline 2 & LUM, AY7, DFO \\
\hline 3 & DFO, AY7, LUM \\
\hline 4 & NIN, DFO, AY7 \\
\hline 5 & LUM, DFO, AY7 \\
\hline 6 & AY7, DFO, LUM \\
\hline
\end{tabular}

AY7 and DFO were replaced with $\mathrm{AB} 1$ and ninhydrin for enhancement on white polyester 


\section{RESULTS AND DISCUSSION}

\subsection{Ninhydrin}

Footwear impressions in blood on dark coloured fabrics and enhanced with ninhydrin did not demonstrate good contrast with the background and no enhancement was observed. The enhancement achieved on light coloured fabrics, however provided good contrast as illustrated in figures 1 and 2. The background staining on white nylon/lycra, illustrated in figure 3, covered the whole fabric, obliterating the original impression in the process. This background staining is due to a reaction between the amide bonds in the nylon structure and ninhydrin. Background staining on other light-coloured fabrics such as cotton and polyester was not as prominent as that observed on nylon/lycra. In some instances, the bright purple colour from ninhydrin enhancement appeared to be brighter after a few hours. reaching a maximum brightness after about 24 hours. The enhancement of footwear impressions in blood on denim using ninhydrin was very weak due to the low contrast between the blue colour of denim and ninhydrin's Ruhemann complex with the amino acids in blood.
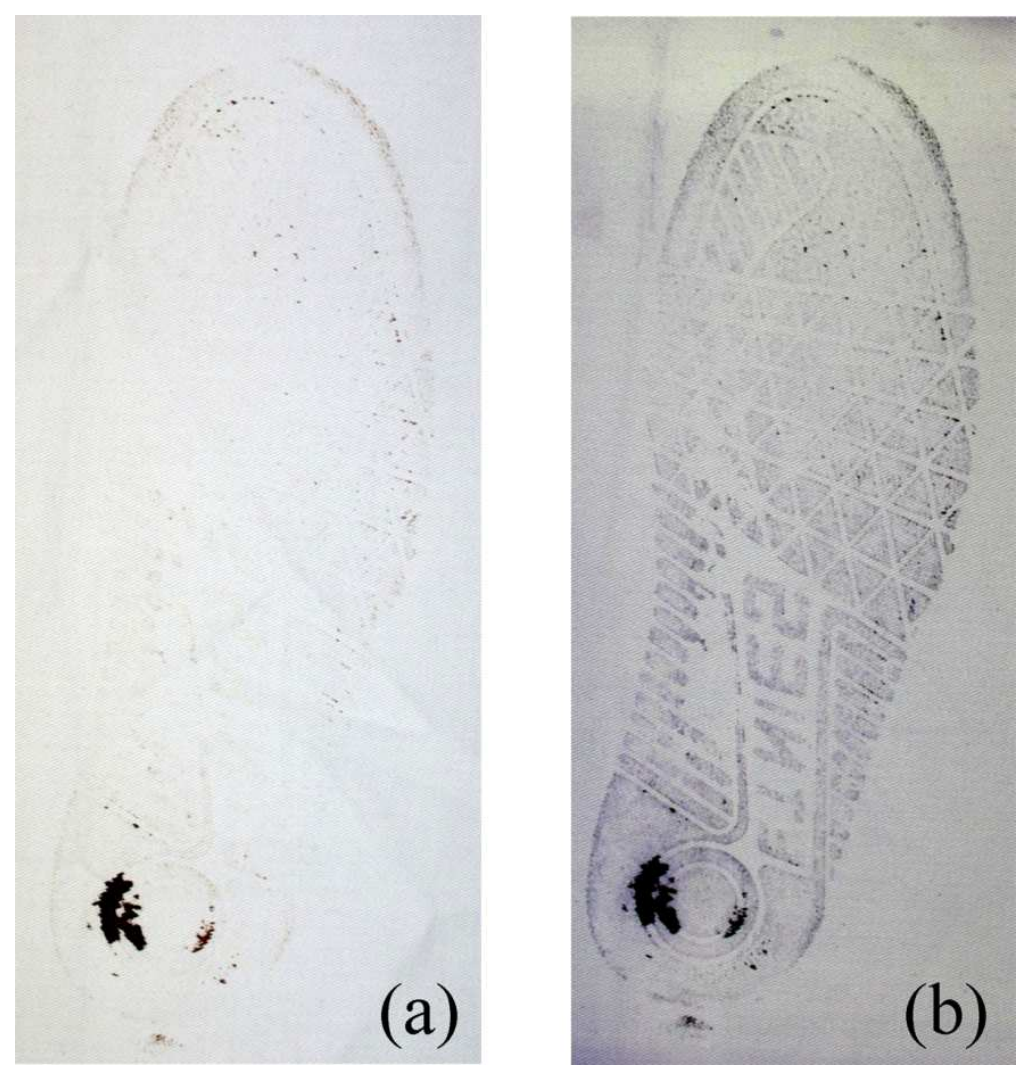

Figure 1 - Enhancement of a footwear impression in blood on white cotton using ninhydrin: (a) before; (b) after 

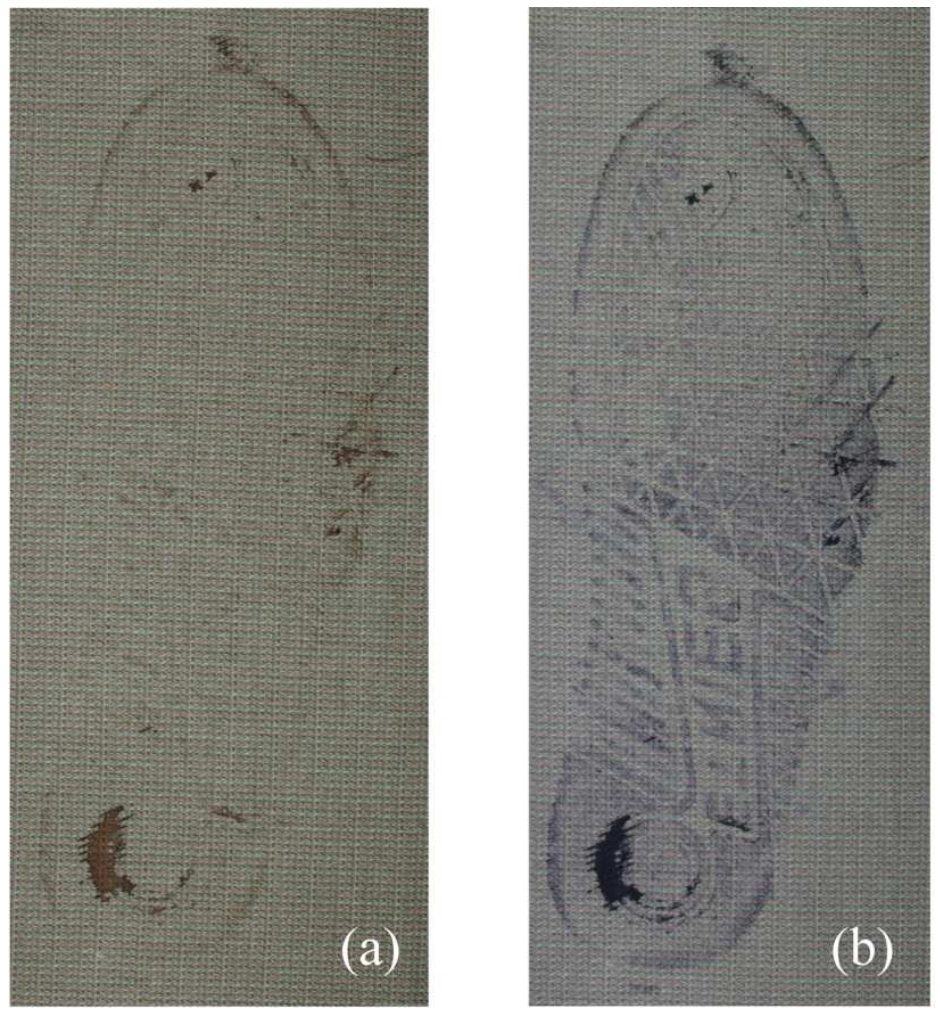

Figure 2 - Enhancement of a footwear impression in blood on patterned cotton using ninhydrin: (a) before; (b) after
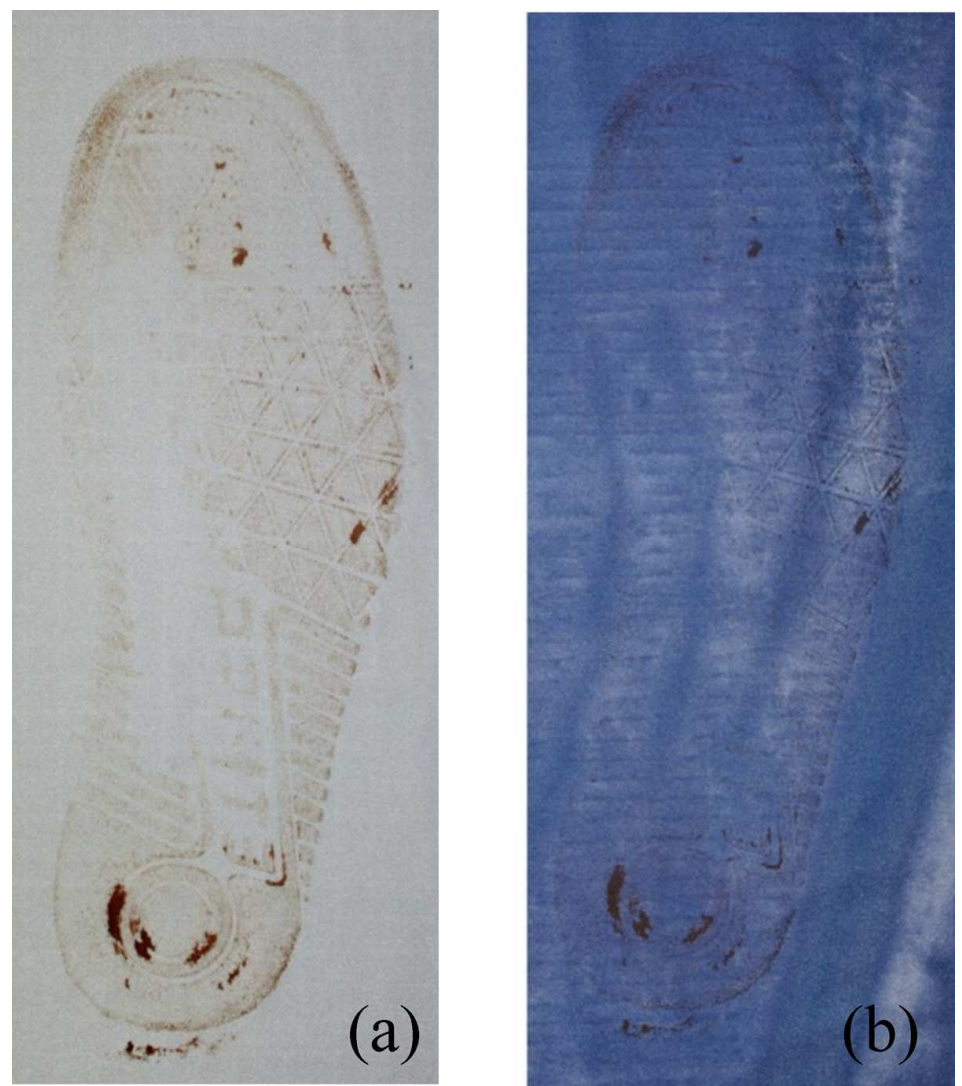

Figure 3 - Enhancement of a footwear impression in blood on white nylon/lycra using ninhydrin: (a) before; (b) after 
The treatment of articles with ninhydrin is quick and straightforward. Furthermore, ninhydrin is able to develop latent impressions as well as those in blood and urine [23] making the technique an attractive option. Drying times are very short since HFE-7100 is very volatile. However, HFE-7100 is an expensive solvent and the procedure requires treatment of articles in an oven that can control humidity and temperature.

\subsection{DFO and 1,2-IND}

Very weak or no enhancement of impressions in blood on fabric was achieved using DFO as illustrated in figure 4. The application of DFO was similar to ninhydrin with the use of a dry oven. DFO required the use of two expensive solvents: HFE-7100 and HFE-71DE, however, it has the potential advantage of fluorescence. The literature suggests that DFO only reacts with minute traces of blood $[24,25]$. To test this hypothesis, a diminishing series of footwear impressions in blood was prepared on white and patterned cotton. Again, no enhancement (visual or fluorescent) was achieved. Similar to DFO, no enhancement of impressions in blood on fabric was obtained with 1,2-indanedione. The lack of fluorescence may be explained by the interaction of the fabric dyes with the enhancement chemicals leading to fluorescence quenching [23].
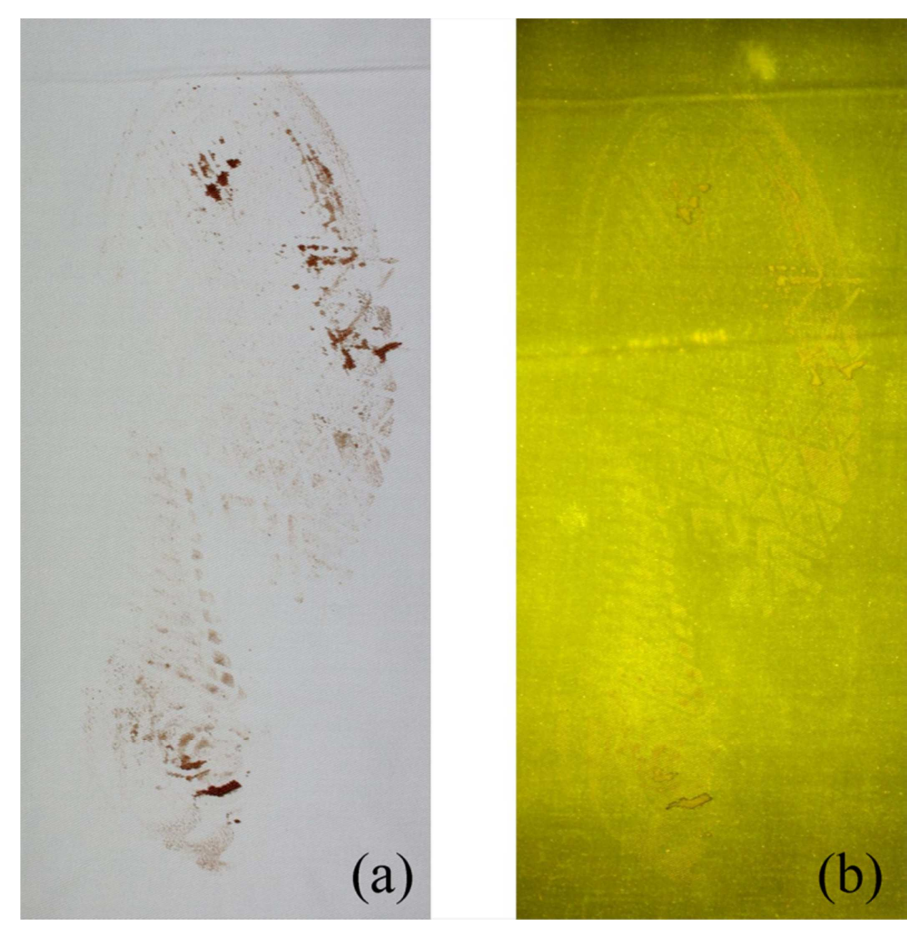

Figure 4 - Enhancement of a footwear impression in blood on white cotton using DFO: (a) before; (b) after 


\subsection{Sequential Chemical Enhancement}

The sequential chemical enhancement of footwear impressions in blood on fabric was attempted using techniques that target different components in blood such as proteins (acid black 1 and acid yellow 7), iron/haemoglobin (luminol) and amino acids (ninhydrin, DFO). Acid black 1 and ninhydrin were used for enhancement of impressions in blood on white polyester whereas acid yellow 7 and DFO were used for enhancement on black cotton to provide the added advantage of fluorescence when possible. These two fabrics were selected as exemplars of light and dark as well as synthetic and natural fibres. Table 2 illustrates the different sequences attempted.

The main observations during these sequences were that luminol gave no or very weak chemiluminescence when applied after ninhydrin or DFO. Luminol enhancement was also poor after the use of protein stains, however, the effect was not as pronounced as that obtained when luminol was used after ninhydrin and DFO. It also appeared that one technique would give suitable results without the requirement of sequential techniques: for example AY7 fluorescence gave superior results when utilised on its own rather than in sequential treatment with luminol. The use of protein stains and ninhydrin after luminol did not demonstrate any deterioration of the impression. Figure 5 illustrates the sequential chemical enhancement of a footwear impression in blood on polyester using luminol followed by ninhydrin and $\mathrm{AB} 1$ whereas figure 6 demonstrates the sequential chemical enhancement of a footwear impression in blood on black cotton using luminol followed by DFO and AY7. The flow chart for the processing of fingerprints in blood, as described in the Manual of Fingerprint Development Techniques, also suggests that ninhydrin and DFO should precede the use of protein stains. In addition, as observed previously, the lack of fluorescence after DFO enhancement may be explained by the interaction of the fabric dyes with the enhancement chemicals leading to fluorescence quenching.

Diffusion and obliteration of the original footwear impression, especially on porous surfaces, is a possibility when using one technique therefore extra caution is necessary when using sequential treatment. The use of one technique might provide suitable enhancement, however, if sequential treatment is attempted, the use of luminol as a first technique is recommended. 

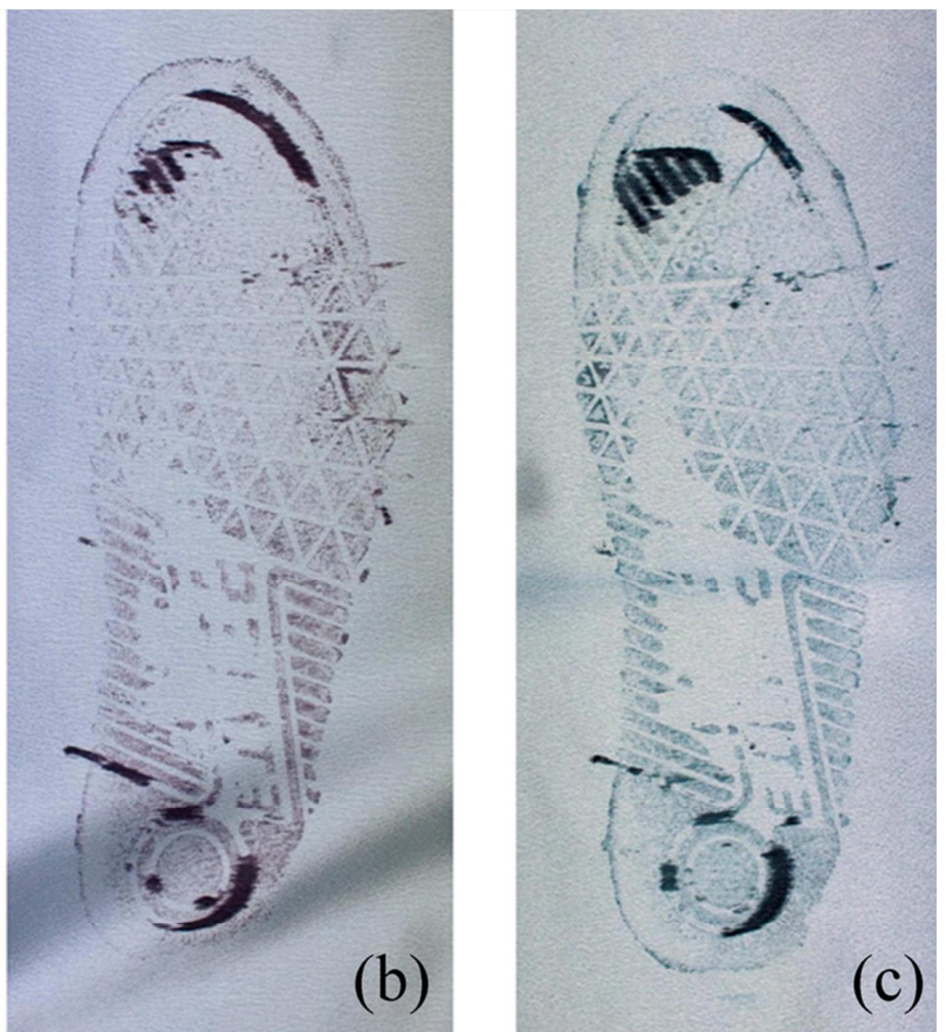

Figure 5 - Sequential chemical enhancement of a footwear impression in blood on white polyester: (a) luminol; (b) ninhydrin and (c) acid black 1 (AB1)
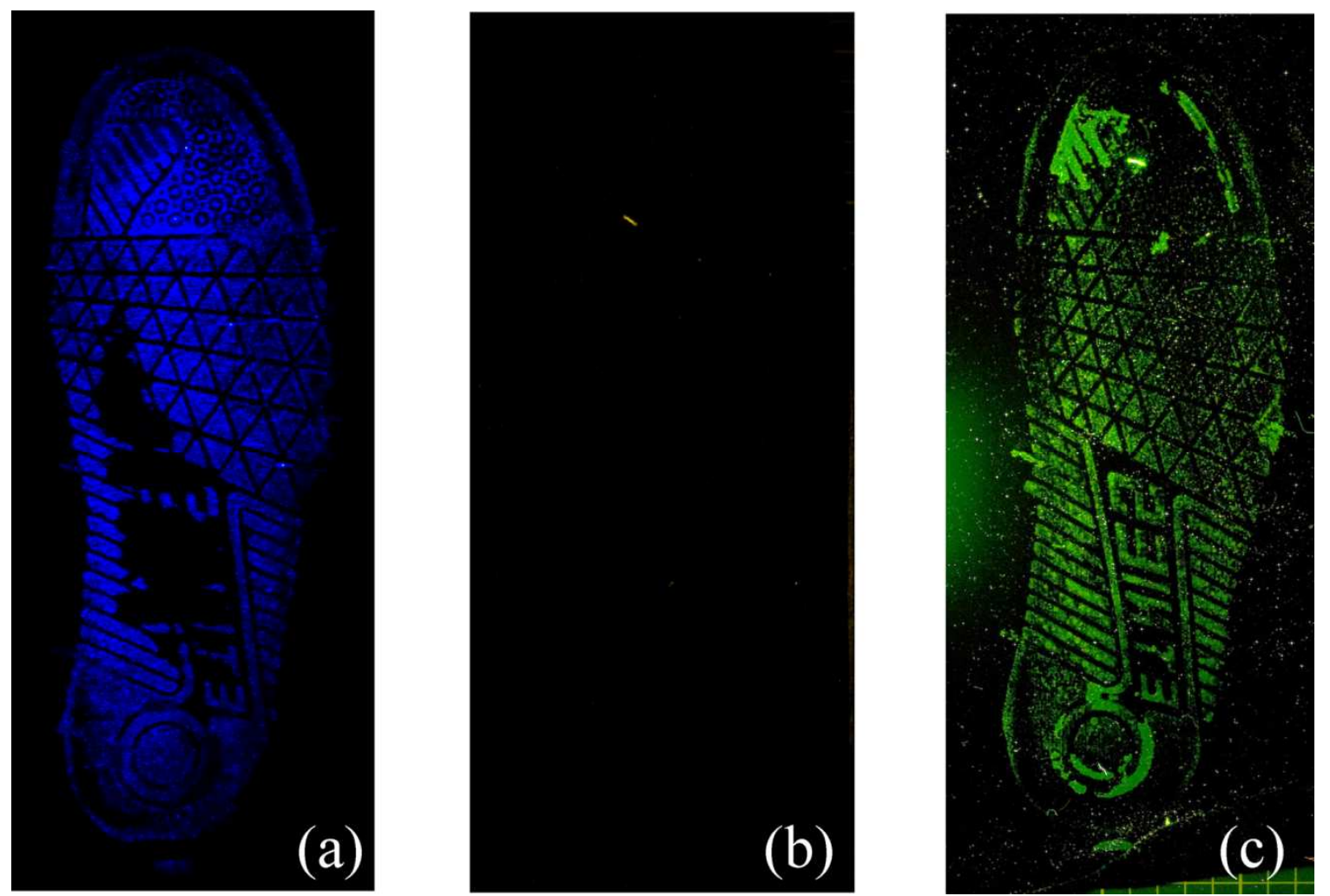

Figure 6 - Sequential chemical enhancement of a footwear impression in blood on black cotton: (a) luminol; (b) DFO and (c) acid yellow 7 (AY7) 


\section{CONCLUSION}

Ninhydrin successfully enhanced footwear impressions in blood on light coloured fabrics with background staining issues on nylon/lycra. The use of DFO and 1,2-IND did not yield any enhancement on impressions in blood on all fabrics possibly due to fluorescence quenching. Design features of the footwear outsole were recoverable and examples include the fine detail of the lettering on the outsole, however individual characteristics (such as cuts) were not visualised most likely because of the weave of the fabric rather than the capability of the enhancement technique. Future work will investigate the effect of fabric dyes on the enhancement mechanism as well as pseudo-operational trials of the enhancement techniques on impressions in blood on fabric. 


\section{Acknowledgements}

The authors would like to thank CAST, EPSRC and the University of Strathclyde for the financial support. This work was also partially funded by the Malta Government Scholarship Scheme. 


\section{REFERENCES}

1. C. Champod, C.J. Lennard, P. Margot, M. Stoilovic, Fingerprints and Other Ridge Skin Impressions, CRC Boca Raton: Florida, 2004

2. H.C. Lee, R.E. Gaensslen, Advances in Fingerprint Technology, 2nd ed, CRC Press LLC: Florida, 2001

3. R.S. Ramotowski ed. 2001. Composition of Latent Print Residue. 2nd ed. Florida: CRC Press Boca Raton.

4. W.J. Bodziak, Footwear Impression Evidence: Detection, Recovery and Examination, 2nd ed, CRC Boca Raton: London, 2000

5. R.K. Morgan-Smith, D.A. Elliot, H. Adam, Enhancement of Aged Shoeprints in Blood, Journal of Forensic Identification, 59 (1) (2009) 45-50.

6. V. Bowman. 2005. Manual of Fingerprint Development Techniques. 2nd ed. Sandridge, UK: Home Office Scientific Development Branch.

7. D.F. Hewlett, V.G. Sears, An Operational Trial of Two Non-ozone Depleting Ninhydrin Formulations for Latent Fingerprint Detection, Journal of Forensic Identification, 49 (4) (1999) 388-396.

8. D.F. Hewlett, V.G. Sears, S. Suzuki, Replacements for CFC113 in the Ninhydrin Process: Part 2, Journal of Forensic Identification, 47 (3) (1997) 300-331.

9. R. Grigg, T. Mongkolaussavaratana, C.A. Pounds, S. Sivagnanam, 1,8-Diazafluorenone and Related Compounds. A New Reagent for the Detection of Alpha Amino Acids and Latent Fingerprints, Tetrahedron Letters, 31 (49) (1990) 7215-7218.

10. S. Hardwick, V.J. Sears, T. Kent, P. Winefield, Improvements to the Formulation of DFO and the Effects of Heat on the Reaction with Latent Fingerprints, Fingerprint Whorld, 19 (65) (1993).

11. J. Almog, A. Hirshfeld, J.T. Klug, Reagents for the chemical development cf latent fingerprints: Synthesis and properties of some ninhydrin analogues, Journal of Forensic Science, 27 (1982) 912-917.

12. C.J. Lennard, P.A. Margot, M. Stoilovic, R.N. Warrener, Synthesis of Ninhydrin Analogues and Their Application to Fingerprint Development: Preliminary Results, Journal of the Forensic Science Society, 26 (5) (1986) 323-328.

13. R.J. Heffner, M.M. Joullie, Synthetic Routes to Ninhydrins: Preparation of Ninhydrin, 5Methoxyninhydrin and 5-(Methylthio)ninhydrin, Synthetic Communications, 21 (21) (1991) 2231-2256.

14. J. Almog, A. Hirshfeld, A. Frank, H. Grant, Z. Harel, Y. Ittah, 5-Methylthio Ninhydrin and Related Compounds: A Novel Class of Fluorogenic Reagents, Journal of Forensic Science, 37 (3) (1992) 688-694. 
15. A.A. Cantu, D.A. Leben, M.M. Joullie, R.J. Heffner, R.R. Hark, A Comparative Examination of Several Amino Acid Reagents for Visualising Amino Acid (Glycine) on Paper, Journal of Forensic Identification, 43 (1) (1993) 44-66.

16. N. Lemberger, J. Almog, Structure Elucidation of Dyes That Are Formed in the Colorimetric Detection of the Improvised Explosive Urea Nitrate, Journal of Forensic Sciences, 52 (5) (2007) 1107-1110.

17. T. Kent, Standardizing Protocols for Fingerprint Reagent Testing, Journal of Forensic Identification, 60 (3) (2010) 371-379.

18. K.J. Farrugia, N. Nicdaéid, K.A. Savage, H.L. Bandey, Chemical enhancement of footwear impressions in blood deposited on fabric - Evaluating the use of alginate casting materials followed by chemical enhancement, Science \& Justice, 50 (4) (2010) 200-204.

19. K.J. Farrugia, K.A. Savage, H.L. Bandey, T. Ciuksza, N. Nic Daéid, Chemical Enhancement of Footwear Impressions in Blood on Fabric - Part 2: Peroxidase reagents, Science \& Justice, 51 (3) (2011) 110-121.

20. K.J. Farrugia, K.A. Savage, H.L. Bandey, N. Nic Daeid, Chemical Enhancement of Footwear Impressions in Blood on Fabric - Part 1: Protein Stains, Science and Justice, 51 (3) (2011) 99-109.

21. K.J. Farrugia, P. Riches, H.L. Bandey, K.A. Savage, N. Nic Daéid, Controlling the Variable of Pressure in the Production of Test Footwear Impressions, Science \& Justice, 52 (3) (2012) $168-176$

22. V.G. Sears, R. Batham, S. Bleay, The Effectiveness of 1,2-Indanedione-Zinc Formulations and Comparison with HFE-Based 1,8-diazafluoren-9-one for Fingerprint Development, Journal of Forensic Identification, 59 (6) (2009) 654-678.

23. K.J. Farrugia, H.L. Bandey, S. Bleay, N. Nic Daéid, Chemical Enhancement of Footwear Impressions in Urine on Fabric, Forensic Science International, 214 (1-3) (2012) 67-81.

24. M. Stoilovic, Detection of semen and blood stains using polilight as a light source, Forensic Science International, 51 (2) (1991) 289-296.

25. M. Stoilovic, Improved method for DFO development of latent fingerprints, Forensic Science International, 60 (3) (1993) 141-153. 